\title{
Subjective and Objective Analysis of Schedule Delaying Factors for Container Shipping Lines
}

Author(s): Cheng-Wei Lin, Wan-Chi Jackie Hsu, Hui-Ju Su

Source: Journal of International Logistics and Trade 2020; 18(4):181-192

Published by: Jungseok Research Institute of International Logistics and Trade, Inha University

DOI: https://doi.org/10.24006/jilt.2020.18.4.181

The Journal of International Logistics and Trade is an official journal published by Jungseok Research Institute of International Logistics and Trade, Inha University, Korea. JILT welcomes manuscripts that advance the practice and science of logistics, trade, and other related fields.

Frequency: Quarterly (March, June, September, December)

Stable URL: https://www.ejilt.org

The Jungseok Research Institute of International Logistics and Trade is a specialized academic research institute representing Inha University and the Inha Foundation in Korea. The institute aims to become a representative institute in Northeast Asia in the research of logistics and trade.

Stable URL: https://jrieng.inha.ac.kr

(C) Copyright. Jungseok Research Institute of International Logistics and Trade.

This is an Open-Access article distributed under the terms of the Creative Commons Attribution NonCommercial License (http://creativecommons.org/licenses/by-nc/4.0/) which permits unrestricted noncommercial use, distribution, and reproduction in any medium, provided the original work is properly cited 


\title{
Journal of International Logistics and Trade
}

J. Int. Logist. Trade, 2020, Vol. 18, No. 4, 181-192

pISSN : 1738-2122 eISSN : 2508-7592

https://doi.org/10.24006/jilt.2020.18.4.181

https://www.ejilt.org

ARTICLE

\section{Subjective and Objective Analysis of Schedule Delaying Factors for Container Shipping Lines}

\author{
Cheng-Wei Lin ${ }^{1}$, Wan-Chi Jackie Hsu2, ${ }^{2,}$, Hui-Ju Su${ }^{1}$ \\ ${ }^{1}$ Department of Logistics and Shipping, Kainan University, Taoyuan 33857, Taiwan \\ ${ }^{2}$ Graduate Institute of Cultural and Educational Management, Central Taiwan University of Sciences and Technology, Taichung 40601 Taiwan
}

$\begin{array}{ll}\text { Received } & \text { August 21, } 2020 \\ \text { Revised } & \text { November 21, } 2020\end{array}$

Accepted December 21, 2020

*Corresponding author: Wan-Chi Jackie Hsu Graduate Institute of Cultural and

Educational Management, Central Taiwan

University of Sciences and Technology,

Taichung 40601, Taiwan

Tel: +886-2-23969314

E-mail: 108281@ctust.edu.tw

\begin{abstract}
The shipper selects a suitable shipping route and plans for a voyage in order to import and export cargo on the basis of published sailing schedules. The reliability of the sailing schedule will influence the shipper's logistics expense, which means that the logistics costs will depend on the reliability of schedules published by container shipping companies. Therefore, it is important to consider factors which can cause delays would for container ships sailing on sea routes. The reliability of published sailing schedules can be affected by a number of different factors. This study adopts the multi-criteria decision making (MCDM) method to estimate the importance of the delaying factors in a sailing schedule. In addition, the consistent fuzzy preference relations (CFPR) method is applied to identify the subjective importance (weights) of the delaying factors. The entropy weight method combined with the actual performance of the container shipping company are both used when estimating the objective importance (weights) of the delaying factors. According to the analysis results, the criteria can be divided into four quadrants with different management implications, which indicate that instructions for chase strategy, sailing schedule control, fleet allocation, transship operation arrangement and planning for ports in routes are often ignored by container shipping companies. Container shipping companies should consider adjusting their operational strategies, which would greatly improve their operational performance.
\end{abstract}

Keywords Container shipping company, Sailing schedule, Consistent fuzzy preference relation (CFPR), Entropy, Multi-criteria decision making (MCDM)

\section{Introduction}

Most global import and export trade rely on marine transport to deliver goods. Therefore, marine transport is crucial to the industrial supply and delivery chain. In order to obtain the greatest economic returns, it is important to deliver the goods to customers quickly and on-time. Companies usually use the sailing schedule published by the container shipping companies to select the appropriate route when arrange for their import and export operation. If container shipping companies can deliver the goods on-time, this can reduce the costs associated with logistics, meaning that accuracy in the schedule and reliability are important to the customer. However, there are a large number of operational factors and other factors that occur in transit that can affect the accuracy of the schedule, such as port operation delays, changes in weather conditions at sea and ship machinery failures, resulting in shipment delays. All of these incidents can lead to an increase in the shipper's logistical costs and damage to the reputation of the container shipping company. Some of the issues related to schedule accuracy have been discussed in previous studies. Chung (2011), for example, has indicated that the quality of service and schedule reliability may impact the negotiation of freight rates between the carrier and the shipper, and affect the operational performance of the container shipping company. Vernimmen et al. (2007) argued that if the shipper did not obtain sufficiently accurate schedules from carriers, they must adopt relevant preventive measures in order to reduce loss and risk. Notteboom (2006) suggested that enhanced shipintensive improves the reliability of delivery time, allowing shippers to reduce logistics costs. Achieving a just on-time model can effectively improve the overall supply chain value.

Chung (2011) used the fuzzy analytic hierarchy process (AHP) to identify the most important schedule delaying factors. However, AHP is a subjective weighting process and objective information may be ignored. That is, the criteria actually influencing the schedule accuracy may not be the same criteria judged important by the shipping companies. This is why the 
CFPR method is used to identify and rank the importance of delaying factors in our study. The CFPR is different from the AHP method, in that there are significantly fewer expert questionnaire items for the same number of criteria, which can enhance the efficiency of the experts in completing the questionnaires. The goal of the CFPR method is to obtain the subjective weight, so we want to apply the entropy weight method, and to find the objective weight, and compare the result obtained with the two methods to identify factors often overlooked.

This study is based on helping container shipping companies to improve the accuracy of their scheduling. Delaying factors for assessment criteria used to construct the schedule are gathered from a literature review and interviews with experts. In addition, the CFPR, which is a subjective weighting technique was applied to analyze the expert preferences, while the entropy weight method was used to obtain the objective weight of the status of shipping company's performance. Finally, the impact of the delaying factors on the schedule was analyzed and the objective and subjective weights compared. The study aims to confirm the effect of delaying factors on the schedule, the subjective and objective weighting of the delaying factors, and to compare the importance of these subjective and objective weight, in order to provide the optimal strategy for container shipping companies to review and improve the assessment of delaying factors, and enhance the stability of logistics management by the shipper.

\section{Literature Review}

There are two main directions examined in the literature review: what are the factors delaying sailing schedules and the methodologies applied in this research. Regarding the delaying factors, related studies include assessment of the port selection, safety operation, service performance and competitiveness. In the methodologies section, related studies on CFPR and entropy methods are investigated.

Port operations are important for the overall logistics and supply chain development which are closely related. The port operating performance is likely to affect the flow of a ship in the port, which can lead to schedule uncertainty and fluctuations in logistics costs for the container shipper company. In other words, choosing a port with a good operating performance will be helpful to enhance the accuracy of the schedules and reduce excess logistics costs. Thomas (1985) points out that container shipping companies should consider the aspects of economic geography, ports and container terminals when selecting major ports and configuring their routes. Also, Abdul et al. (2019) point out that ports and their stakeholders significantly affect the actual transport plans and cost of handing cargo. The earliest performance indexes provided by Plumlee (1979) included the cargo performance index, berth performance index, port performance index, ship congestion index and cargo dwell time index, which means these criteria should be considered when constructing related criteria of port. Hoffmann (1985) tested the unit cost productivity of ports based upon the concept of cost efficiency. The provided six operation performance indexes for ports, including berth occupancy, berth throughput, ship turnaround time, productivity, dwell time and the utilization of equipment. These indexes serve as the basis for managerial planning when implementing berth assignment plans and the purchase of charging cranes. Pham and Yeo (2019) think terminal accessibility and the proximity to a main trunk route are the most important. Kaliszewski et al. (2020) pointed out terminal service quality, labor and nautical accessibility are important when considering shipping companies operations. Besides the factors of ports, factors about human are also should be considered, which is introduced by Weng et al. (2019). In a related study, Murphy et al. (1991) identified the criteria for port selection in their investigation of port authorities and high-level managers. Slack (1985) derived a choice model of shippers and freight forwarders selecting ports through questionnaire investigation, which also provided important evaluation criteria for our research. Yang and Chang (2019) pointed transportation capability, external risks, information integration, logistics infrastructure, local agents' logistics capability, and national law and policy were crucial factors of operations.

The factors influencing navigation efficiency should include those related to ship cargo management and equipment maintenance. That is, navigational operations directly affect the efficiency and safety of maritime transport. Ship sailing operations should take into account good management of ships. Kristiansen (2005) categorized six causes, including external conditions, equipment failure, negligence of other ships, lack of information, shortage of resources and navigation errors, based upon statistical data for 419 stranded ships with a total of 1599 ship tons. Yang and Chang (2019) provide crucial factors of shipping operations including Transportation capability, external risks, information integration, logistics infrastructure, local agents' logistics capability, and national law and policy were crucial factors.

To enhance service performance and competitiveness it is necessary to improve the effectiveness and time utility of regional cargo transportation. To do this container shipping companies need to execute plans for the overall arrangement of internal resources, routes and schedule integration. Notteboom (2006) analyzed all transit strategies between sea and land according to 
the related analysis of marine service time and influential factors for constructing schedules. McGinnis (1979) applied factor analysis methods in their discussion of the market segmentation of shipping carriers. The results reveal that the shippers pay much more attention to the transportation speed and reliability of the sailing schedule, which are the important criteria for choosing a shipping company. Brooks (1990) investigated the major factors for choosing shipping companies in Canada during the period from 1982 to 1989, concluding that the most important factors are transportation time arising from voyage frequency and transportation cost. Based on the literature review above, it can be concluded that the criteria in the aspects of port, human ability and management should be considered when dealing with the service performance problem of shipping companies.

When dealing with the evaluation problems, identifying the relative weights of criteria is the next step. AHP is a popular method to find the weights of criteria. Abdul et al. (2019) applied AHP as the main methodology to find the relative weights of delay factors on dry bulk cargo operation. Lee et al. (2020) and Seo et al. (2019) also applied AHP to deal with the logistics and shipping problems, respectively. Analytic Network Process (ANP) is also an often-adopted method to deal with evaluation problems. Besides, Fuzzy theory is also combined with related weighting methods to measure the experts' perception. such as Ding (2011) applied fuzzy analytic hierarchy process (FAHP) approach and the entropy weighting method to identify the criteria weights. Owing to these methods are complicated when dealing with the practical problems, Herrera-Viedma (2004) proposed that the CFPR method can easily solve the problems, and this method is widely used to measure and compare the importance between factors. For example, Wang and Chen (2007) applied the CFPR method to construct an efficient selection model for enterprise partners. Chao and Chen (2009) used the CFPR method to calculate the weight and obtain the degree of importance of each factor used to analyze the effectiveness of an e-learning system. This served as an important basis for assessment of the system. Ma et al. (1999) and Xu (2004) pointed out that weights can be obtained by applying both subjective and objective weights. Subjective weights are obtained by collecting the perceptions of decision-makers. Suthiwartnarueput et al. (2020) applied CFPR combined with PROMETHEE to deal with the problems of waterfront development. Also, Lee et al. (2014) applied similar methodologies to find the relative weights of financial positions of shipping companies. However, if there are too many criteria, evaluation is extremely difficult, an adequate questionnaire can be almost impossible to design, which will also cause the results (weights) to be unreliable. It has been found that the CFPR can solve such issues and so has been applied widely in related research areas, which is why we utilize this method to deal with our problem.

Besides the methods mentioned above, there are another weight identified method, Entropy, which is introduced by Shannon (1948). The entropy weight method has also been widely used in a variety of different fields, such as Jee and Kang (2000) utilized the theories of entropy to evaluate the weight factor for each material property or performance index; Chan and Wu (2005) adopted entropy method to conduct competitive analysis and derive competitive priority ratings for a case of fried Chinese vegetable; Zhang et al. (2006) estimated the year-and indicator-based information entropies for the urban ecosystem for the progress of sustainable development of Ningbo City in China from 1996 to 2003; Liu et al. (2010) applied fuzzy theory and information entropy for water quality assessment in China; Hsiao and Chou (2006) used a fuzzy entropy for home page design; Chen et al. (2018) used an entropy weighted grey relation analysis method to analyze key contributors to oil spills, and evaluates the extent of impacts of each factor in different ship operations. Lee et al. (2018) adopted entropy to find the relative weights of financial ratios of the four shipping companies each year based on the financial performance. Chen et al. (2019) used grey rational analysis (GRA) model with improved entropy weight to analyze the factors behind the detention of ships under port state control (PSC). In recent years, there are a lot of researches applying this method to evaluate the weights of criteria, such as Liu et al. (2017), Li et al. (2011), Li et al. (2019) and Lin et al. (2020). All these researches applied Entropy to identify the relative weights of criteria by the performance of alternatives. One problem should be mentioned is the input data of Entropy is different from AHP. The weights of AHP are derived from the experts' perception by questionnaires, which means the weights derived by these two methods are different. What are the characteristics of these two methods? Chen (2019) pointed out that the diversity of criteria data will influence the decision results. Which means the weights of Entropy are derived by the criteria data, but not the experts' perceptions. In this paper, we name it as subjective weighting method (AHP) and objective weighting method (Entropy). Shannon (1948) first proposed the entropy method to calculate the weights of the criteria in an objective fashion, without needing to collect subjective perceptions by the decision-makers, but needing to determine the performance value of alternatives for each criterion. The entropy weight method is usually used as a mathematical measure of uncertainty. When the diversity in the performance value of alternatives is large it means that the criterion is important (Zou et al. 2006).

\section{Research Methodology}

As noted above, two methods are used in this study, the CFPR and entropy weight methods, to identify the objective and 
subjective weights of delaying factors for container shipping companies. These objective and subjective weighting methods are applied to find the relative criteria weights of the delaying factors. The objective weighting method, the entropy method, utilizes the performance of shipping companies to identify the relative weights, while on the other hand, the subjective weighting method, CFPR, utilizes a pairwise comparison matrix to find the relative weights of the criteria. The ignored criteria are found through a comparison of the objective and subjective weights identified by the entropy weight and CFPR methods. The research framework is shown in Figure 1 below. A questionnaire is designed to investigate the pairwise comparison of criteria importance and the performance of shipping companies, with responses used to find the objective and subjective weights of the criteria.

The objective weights are measured by looking at the variance for alternative performances. The criteria are less important when the alternative performances are closer together. Subjective weights are investigated by questionnaire and measure the perceptions of decision makers. In other words, the relative weights are measured by experts according to their knowledge in the related area. The operational steps of these two methods are described in the following sections. Operation flowcharts are provided to clarify descriptions of the concepts. The two methods are described in detail in Lee et al. (2014), including definitions of the related equations.

CFPR was introduced by Herrera-Viedma et al. in 2004, and has become well-known as an efficient subjective weight identification method. According to past research there are five steps required to measure the relative weights. First of all, the initial decision matrix is constructed from pairwise comparison questionnaire responses. With this method the respondents do not have to answer a lot of questions. In the second and third steps, the researcher can complete the partial decision matrix using the fuzzy preference relations, which makes each cell of the decision matrix conform to the consistency demand. In the fourth step the relationship is transformed into the desired range depending upon the possibility that the transformation results may generate unreasonable results. This step ensures that all of the values in the matrix cells are reasonable and consistent with the experts' judgment. In the last step, the final subjective weights are calculated based upon the justified decision matrix. The steps in the operation are shown in Figure 2 below.

The entropy method is well-known as a simple objective weighting method, which utilizes alternative performances to identify the relative weights. There are four steps to identify the objective weights for the evaluation criteria. The first step is to find the performance matrix either using real performance data or by experts' ratings. Due to there being different units of criteria, all the information (data) should be normalized to make related calculation reasonable, which is done in the second step. After the related information is collected and normalized, the entropy weights can be calculated in step 3 . Under the same conditions as for the CFPR, unreasonable weights may appear in the entropy weight results. In the last step, a transformation equation ensures that the objective weights are scaled in $[0,1]$. The operational steps can be found in Figure 3 below.

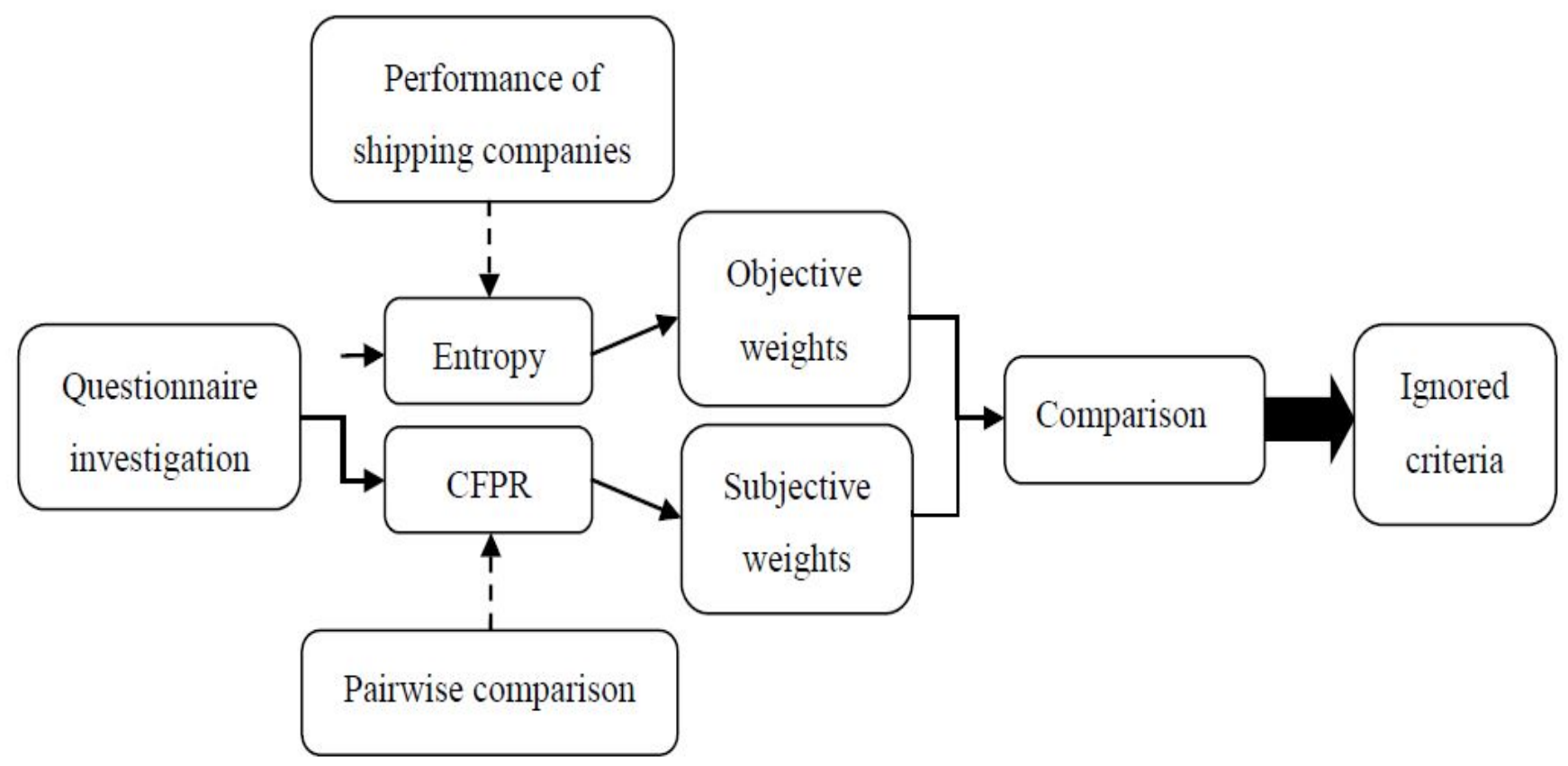

Figure 1. Conceptual diagram of objective and subjective weighting methods (CFPR, consistent fuzzy preference relation). 


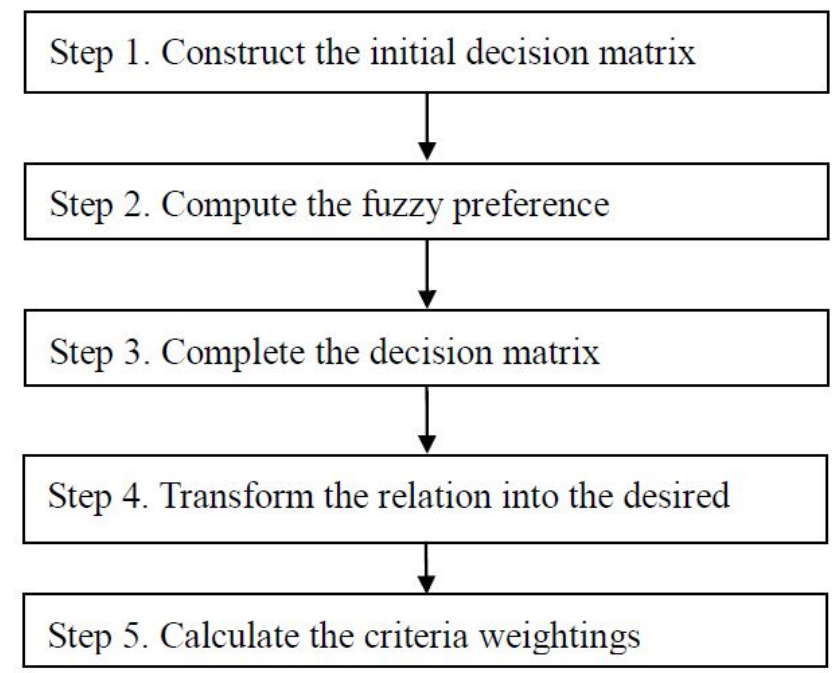

Figure 2. The operational steps of CFPR (CFPR, consistent fuzzy preference relation).

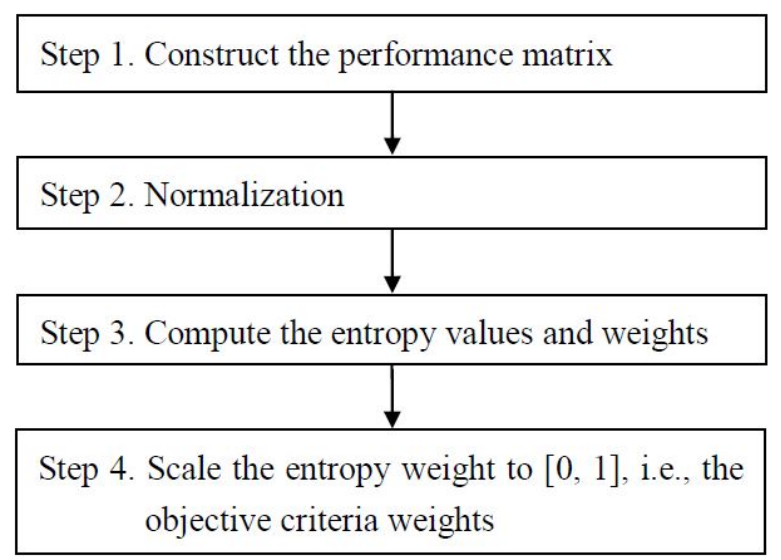

Figure 3. The steps in the entropy operation.

\section{Empirical Analysis}

This study used both subjective and objective weighting methods. The main purpose is to find the relative importance of delaying factors based on experts' perceptions and to provide some suggestions for container shipping companies when constructing sailing schedules. Additionally, information about the performance of the container shipping companies can be collected by the rating of experts or practical data collected from shipping companies, from which the objective weights can be found, information that is often ignored in subjective weighting methods. Eleven questionnaire responses were collected from experts in the Taiwanese maritime industry.

\subsection{Evaluation hierarchy of delaying factors}

The evaluation hierarchy, shown in Table 1, is constructed. Three aspects constructed based on the literature review mentioned in the second part of this paper. The evaluation criteria are generated based upon past related research, brain-storming and interviews with experts of shipping companies. Aspect A (Planning) suggests that shipping companies should pay more attention to ship maintenance, in order to avoid unexpected malfunctions that can cause delays; Aspect B (Ability) encourages the port authorities to exercise good communication and coordination, to prevent waiting times at the dock; Aspect C (Port) pertains to the port authorities arranging the appropriate berths and warehouses to allow the ship to proceed with loading and unloading operations immediately upon arrival at port. 
Table 1. Evaluation hierarchy for delaying factors

Aspects/criteria

(A) Planning aspects

(A1) Planning for ports along routes

(A2) Fleet allocation

(A3) Sailing schedule control

(A4) Transshipment arrangements

(A5) Ship repair and maintenance

(B) Ability aspects

(B1) On time bonus for crews

(B2) Training superior captains

(B3) Port coordination skills

(B4) Chase strategy

(B5) Coordination ability of staff

(C) Port aspects

(C1) Time window arrangement for quays

(C2) Shorten mooring time

(C3) Port-road connections

(C4) Appropriate berths deployment

(C5) Improve port operations
Definition

The factors of berthing, ship size, flight distance, ship speed, cargo amount and port restrictions should be considered for route planning and port selection.

The arrangements for route planning, fleet selection, crew training, the implementation of the voyage, stevedoring at port and warehousing shall be linked smoothly to make the sailing schedule accurate.

The sailing schedule must be arranged by strict standard operating procedures (SOP). It could easily cause delays if based solely on subjective judgments or rule of thumb.

Suitable transshipment arrangements can have a positive impact on preserving the schedule accuracy.

The utilization of equipment varies. The repair and maintenance of equipment should be emphasized to avoid schedule delays caused by mechanical failure.

The members of the crew are the first line workers operating the ship. Effective functioning will enhance schedule accuracy. Companies can provide an on time bonus to the crew for preserving sailing schedule accuracy.

Training superior captains is an important basic task for shipping companies.

To reduce the waiting time, the port agents of shipping companies should be able to coordinate efficiently with the port authorities, customs, pilot stations, stevedoring companies and port agencies.

The chase strategy in case of schedule delays needs to proceed according to the best management standards and the associated contract content.

The shortage, slowdown or lack of dock workers can cause serious delays in the sailing schedule; therefore, port agents must ensure that the dock workers provided are sufficient.

The container shipping company usually chooses a preferred time for docking to save operating costs. If the time window for docking is not arranged properly, it will adversely affect the sailing schedule.

The outer mooring time includes a buffer time for related operations at ports meant to absorb delays in terminal operations or getting in or out of terminals.

Inland transport connections may not be met resulting in portside operational delays when there is not enough space to handle containers or if the connective roads are congested.

Planning appropriate berthing positions in advance before the ship arrives, and ensuring stevedoring immediately upon arrival is important to avoid operational delays.

The problem of port congestion can occur for old port facilities and long stevedoring times. If the operational efficiency of the port is strengthened, the accuracy of the sailing schedule can be improved.

\subsection{Calculation of subjective and objective weights}

This section describes the subjective and objective weights calculated from the questionnaire data.

\subsubsection{Subjective weights of delaying factors}

The subjective weights in CFPR are calculated by pairwise comparisons. The results are summarized in Table 2. The subjective weights reveal the importance of various delaying factors faced by container shipping companies as evaluated by experts. The local weights explain the sum of the relative importance of the criteria in the same dimension; that is, the sum of the local weights in each dimension is equal to 1 . In Table 2, the local weights are not shown for the reason that they are trivial. On the other hand, the global weights represent the relative weights of the evaluation criteria from an overall viewpoint. The weights for aspect B (Ability) and aspect C (Port) are close, 0.346 and 0.351 , respectively.

It can be seen that the top 5 highest weighted criteria belong to aspect $B$ (Ability) and aspect $C$ (Port), which means these two aspects are more emphasized by the experts. C4 (Appropriate berths deployment), C5 (Improve port operations) and B3 (Port coordination skills) are the top 3 factors with weights higher than 0.075 and belong to the port aspect. This means that 
Table 2. Subjective and objective weights for ranking of the evaluation criteria

\begin{tabular}{|c|c|c|c|c|}
\hline Criteria & CFPR & Ranks & Entropy & Ranks \\
\hline (A) Planning aspects & 0.3033 & & 0.396 & \\
\hline (A1) Planning for ports along routes & 0.060 & 13 & 0.065 & 6 \\
\hline (A2) Fleet allocation & 0.049 & 15 & 0.084 & 3 \\
\hline (A3) Sailing schedule control & 0.062 & 12 & 0.091 & 2 \\
\hline (A4) Transshipment arrangements & 0.065 & 11 & 0.081 & 4 \\
\hline (A5) Ship repair and maintenance & 0.068 & 6 & 0.074 & 5 \\
\hline (B) Ability aspect & 0.3456 & & 0.323 & \\
\hline (B1) On time bonus for crews & 0.067 & 7 & 0.061 & 9 \\
\hline (B2) Training superior captains & 0.070 & 5 & 0.045 & 15 \\
\hline (B3) Port coordination skills & 0.075 & 2 & 0.065 & 6 \\
\hline (B4) Chase strategy & 0.066 & 10 & 0.102 & 1 \\
\hline (B5) Coordination ability of staff & 0.067 & 7 & 0.050 & 13 \\
\hline (C) Port aspects & 0.3511 & & 0.281 & \\
\hline (C1) Time window arrangement for quay & 0.067 & 7 & 0.057 & 10 \\
\hline (C2) Shortening mooring time & 0.060 & 13 & 0.057 & 10 \\
\hline (C3) Port-road connections & 0.072 & 4 & 0.048 & 14 \\
\hline (C4) Appropriate berths deployment & 0.077 & 1 & 0.065 & 6 \\
\hline (C5) Improve port operations & 0.075 & 2 & 0.054 & 12 \\
\hline
\end{tabular}

CFPR, consistent fuzzy preference relation.

port operation related factors are more emphasized. Additionally, C3 (Port-road connections), B2 (Training superior captains) and A5 (Ship repair and maintenance), ranked at 4, 5 and 6, belonging to the equipment aspect, can be categorized with the port aspects. It can be concluded that port performance should be the most important aspect when considering delaying factors for ship arrival.

\subsubsection{Objective weights of delaying factors}

The objective weights, shown in Table 2, are obtained from the entropy weighting method, based upon the performance of shipping companies in terms of the related delaying factors. It can be seen that the subjective weights and objective weights are different. According to the weight distribution of delaying factors in each aspect, different factors are emphasized. Aspect A (Planning) which represents planning operations related to schedule arrangement are more important than ship repair and maintenance. Aspect B (Ability) related to implementing an appropriate chase strategy is more important than the other factors. The objective and subjective weights of aspects C (Port) are the same, indicating that appropriate berthing and warehouse arrangements before ship arrival is the most important to ensure more efficient operational performance. In addition, the objective weights indicate that aspect A is higher than aspect B, and aspect B is better than aspect C, with weights of 0.396, 0.323 and 0.281 , respectively.

The top 3 factors when considering global weights are B4 (Chase strategy), A3 (Sailing schedule control) and A2 (Fleet allocation), whose relative weights are all higher than 0.080 . The importance of the top 3 factors suggest that an appropriate chase strategy should be implemented in case of schedule delays. A3 (Sailing schedule control) and A2 (Fleet allocation) should also be emphasized at this time. Since the objective weight is assigned based on the current performance of the shipping companies, then speaking overall, the top 3 factors are the ones that should be strengthened to make for better performance. On the other hand, it is unnecessary to make much effort to strengthen the bottom 3 factors because they do not have a big effect on consistency of performance (best or worst).

\subsubsection{Comparison of subjective and objective weights}

Past studies of delaying factors have mainly focused on evaluation by expert opinions, but ignored the objective viewpoint. This work tries to fill this gap by applying objective weighting methods to find the objective weights and provides a comparison and analysis for these two kinds of weights. The difference of experts' perception in subjective and objective weights obtained are shown in Table 3. Range represents the difference of expert's perception, which is the distance between highest and lowest 
Table 3. Difference in values of subjective and objective weight

\begin{tabular}{|c|c|c|c|c|c|c|}
\hline \multirow[t]{2}{*}{ Criteria } & \multicolumn{3}{|c|}{ CFPR } & \multicolumn{3}{|c|}{ Entropy } \\
\hline & Range & S.D. & C.V. & Range & S.D. & C.V. \\
\hline (A1) Planning for ports along routes & 0.080 & 0.026 & 0.435 & 0.150 & 0.046 & 0.706 \\
\hline (A2) Fleet allocation & 0.085 & 0.024 & 0.487 & 0.116 & 0.032 & 0.378 \\
\hline (A3) Sailing schedule control & 0.072 & 0.023 & 0.365 & 0.176 & 0.057 & 0.629 \\
\hline (A4) Transshipment arrangements & 0.049 & 0.012 & 0.188 & 0.113 & 0.035 & 0.435 \\
\hline (A5) Ship repair and maintenance & 0.041 & 0.010 & 0.154 & 0.138 & 0.033 & 0.450 \\
\hline (B1) On time bonus for crews & 0.041 & 0.010 & 0.154 & 0.137 & 0.043 & 0.701 \\
\hline (B2) Training superior captains & 0.049 & 0.013 & 0.179 & 0.076 & 0.022 & 0.494 \\
\hline (B3) Port coordination skills & 0.058 & 0.015 & 0.201 & 0.095 & 0.025 & 0.391 \\
\hline (B4) Chase strategy & 0.072 & 0.018 & 0.271 & 0.138 & 0.046 & 0.452 \\
\hline (B5) Coordination ability of staff & 0.051 & 0.014 & 0.209 & 0.097 & 0.034 & 0.690 \\
\hline (C1) Time window arrangement for quays & 0.051 & 0.014 & 0.209 & 0.122 & 0.036 & 0.633 \\
\hline (C2) Shortening mooring time & 0.040 & 0.013 & 0.215 & 0.115 & 0.039 & 0.683 \\
\hline (C3) Port-road connections & 0.074 & 0.023 & 0.315 & 0.107 & 0.032 & 0.659 \\
\hline (C4) Appropriate berths deployment & 0.051 & 0.016 & 0.211 & 0.123 & 0.035 & 0.547 \\
\hline (C5) Improve port operations & 0.076 & 0.023 & 0.301 & 0.105 & 0.032 & 0.590 \\
\hline
\end{tabular}

CFPR, consistent fuzzy preference relation; S.D., stand deviation; C.V., coefficient of variation.

value.

Among the results of subjective weights, C4 (Appropriate berths deployment) is ranked as most important, while its objective weight is ranked sixth. Some of the subjective and objective weights are consistent while some are inconsistent. For example, the delaying factors A5 (Ship repair and maintenance), B1 (On time bonus for crews), C1 (Time window arrangement for quays) and C2 (Shortening mooring time) are ranked in the middle and bottom by both subjective (i.e., CFPR) and objective methods (i.e., Entropy). On the other hand, the delaying factors B2 (Training superior captains), B3 (Port coordination skills), C4 (Appropriate berths deployment) and C5 (Improve port operations) were ranked in the top positions by the CFPR but ranked in the middle or bottom positions by the entropy method.

The experts' preferences for related factors are similar, with approximate coefficients of variance (CV), except for A1 (Planning for ports along routes) and A2 (Fleet allocation) which have larger variance, 0.435 and 0.487, respectively. In other words, expert opinion about A1 (Planning for ports along routes) and A2 (Fleet allocation) is not consistent. On the other hand, the variance is higher for objective weights than subjective weights, with the value of the CV distributed between 0.435 and 0.690, except for A1 (Planning for ports along routes) and B1 (On time bonus for crews) with higher CVs of 0.706 and 0.701. These result-different outcomes of two methods-conform to the nature of these two weighting identification methods.

\subsection{Categorization of delaying factors by subjective and objective weights}

The delaying factors are categorized into four quadrants according to the results of the subjective and objective weights, as shown in Table 4. The fifteen delaying factors are assigned to quadrants depending upon the mean value of the objective weight in the column calculated by the entropy method and the subjective weight in the row calculated by the CFPR method.

The delaying factors in quadrant I have higher subjective weights but lower objective weights compared to their mean values. A low objective weight indicates high performance variance and that experts (questionnaire respondents in this research) think these factors are important. The other quadrants are similarly defined. The delaying factors in quadrant II are those with low subjective weights and low objective weights. On the other hand, the delaying factors in quadrant IV have high subjective weighs and high objective weights. It is worth noting that quadrant III includes those factors with lower subjective weights, but higher objective weights compared to their mean values indicating that these factors regarded as unimportant by experts are actually important owing to the low variance of operation performance. Therefore, we can infer accordingly that the factors in quadrant III may have been ignored by the experts. Experts do not appear to place much emphasis on high variance delaying factors, for related factors including B4 (Chase strategy), A3 (Sailing schedule control), A2 (Fleet allocation), A4 (Transshipment arrangements) and A1 (Planning for ports along routes).

After identifying the logical analysis, more details of the comparison analysis are discussed in the following sections. First 
Table 4. Clustering delaying factors by the CFPR and entropy methods

\begin{tabular}{|c|c|c|c|}
\hline & & \multicolumn{2}{|c|}{ CFPR } \\
\hline & & Lower area & Higher area \\
\hline \multirow[t]{4}{*}{ Entropy } & Lower area & Quadrant II & Quadrant I \\
\hline & & (C2) Shortening mooring time & $\begin{array}{l}\text { (C5) Improve port operations } \\
\text { (C3) Port-road connections } \\
\text { (B2) Training superior captains } \\
\text { (B1) On time bonus for crews } \\
\text { (C1) Time window arrangement for quays } \\
\text { (B5) Coordination ability of staff }\end{array}$ \\
\hline & Higher area & Quadrant III & Quadrant IV \\
\hline & & $\begin{array}{l}\text { (B4) Chase strategy } \\
\text { (A3) Sailing schedule control } \\
\text { (A2) Fleet allocation } \\
\text { (A4) Transshipment arrangements } \\
\text { (A1) Planning for ports along routes }\end{array}$ & $\begin{array}{l}\text { (C4) Appropriate berths deployment } \\
\text { (B3) Port coordination skills } \\
\text { (A5) Ship repair and maintenance }\end{array}$ \\
\hline
\end{tabular}

CFPR, consistent fuzzy preference relation.

of all, factors C4 (Appropriate berths deployment), B3 (Port coordination skills) and A5 (Ship repair and maintenance) all have higher subjective and objective weights, which means that some shipping companies do not have good operational performance in terms of these three factors. These companies should first improve their performance in relation to these criteria if they want to improve efficiency. Furthermore, the factors in quadrant III can be considered for improvement if shipping companies want to improve their overall performance. The factors in quadrant III may contribute to improvement even though their relative importance (weights) is rated poorly by experts.

C4 (Appropriate berths deployment), B3 (Port coordination skills) and A5 (Ship repair and maintenance) are the most important factors identified by the subjective weighting method. They are the important factors that shipping companies should pay attention to in order maintain their performance. However, there are a lot of factors that are not under the control of the shipping company which is why cooperation between shipping companies and port authorities is so important.

Factors B4 (Chase strategy), A3 (Sailing schedule control), A2 (Fleet allocation), A4 (Transshipment arrangements) and A1 (Planning for ports along routes) are identified as important by the objective weighting method, which means that shipping companies do not demonstrate consistent performance in relation to these factors. From this viewpoint, it can be inferred that these 5 factors have not been emphasized by the shipping companies, but they can improve their performance in related factors where they have already invested relatively more resources. Of course, the focus is on identifying the directions for improvement and the factors may be ignored.

\section{Discussion}

In the real-world decisions must be carried out individually for each company, and managers and experts play key roles in setting company policies. Other staff members may not argue with the decisions by them. However, it is risky to depend upon professional judgment alone. Experts in the container shipping industry should have professional knowledge, which means they have authority and knowledge when making decisions. The decisions represent not only the directions of operation of their own company, but competitors and partners will refer to them and adjust their own operating decisions accordingly. The subjective weights of delaying factors obtained in this research indicate the common consensus of the experts in this industry. However, the importance of the criteria maybe changed according to the performance of all the companies in this industry. For example, it will be waste allocating amount of resources to the factors that all the companies have good performance. Which means the efficiency of this investment is not good enough. If the managers can find the factors ignored by some of the companies, allocating resources in these factors maybe make great progress and generating good overall performance. There are two contribution of results from two methods. First, subjective weights derived from AHP provide the shipping companies the real important criteria judged by experts. All the companies should pay much attention in this part. However, the function of objective weights are used to remind the shipping companies their performance among this industry.

Factors C1 (Time window arrangement for quays), C3 (Port-road connections), C5 (Improve port operations), B1 (On time bonus for crews), B2 (Training superior captains) and (B5) Coordination ability of staff all have high subjective weights but 
low objective weights, which means they are viewed as the most important criteria by experts in the decision groups. The criteria in quadrant I all have good performances for all container shipping companies considered in this study. C2 (shortening mooring time) is an interesting criterion in the hierarchy owing to the fact although it can improve the delaying conditions, it is categorized in quadrant II, which means it is the least important criterion among the 15 criteria. The most likely reason for this is that the functions of this criteria can be covered by other criteria, such as C1 (time window arrangement for quays), C4 (Appropriate berths deployment) and C5 (improve port operations). These factors can also shorten mooring time in different ways. A5 (Ship repair and maintenance), B3 (Port coordination skills) and C4 (Appropriate berths deployment) from quadrant IV, are evaluated as important by the experts but not all shipping companies have good performance in relation to these criteria. Therefore, the first step to improving the shipping company performance is to find which company did not perform well for the criteria in quadrant IV.

B4 (Chase strategy), A3 (Sailing schedule control), A2 (Fleet allocation), A4 (Transshipment arrangements) and A1 (Planning for ports along routes) are assigned to quadrant III, which means they may have been ignored by the experts. Of these criteria, A1 (Planning for ports along routes), A2 (Fleet allocation) and A4 (Transshipment arrangements) are in the planning dimension, which means that they should be done in advance, so should not have any relationship with A3 (Sailing schedule control) and B4 (Chase strategy). Chase strategy is implemented when the control system (A3) finds that there has been some delay. The first three criteria may have been implemented for shipping companies and the last two criteria may be just a backup system; however, the delaying of sailing schedules is common, which means the backup systems are not working to improve delays. This result is a reminder for related companies to pay more attention to these criteria or systems.

\section{Conclusion}

The purpose of this paper is to identify the importance of factors which can cause delays and disrupt the schedules of container shipping companies by using the CFPR and entropy weighting methods. In addition, the best alternatives for improvement are found according to the results of quadrant diagrams of the subjective and objective weights.

The results of subjective weights reveal that the most important dimension is the port dimension and the top 3 important criteria are C4 (Appropriate berths deployment), C5 (Improve port operations) and B3 (Port coordination skills). These results suggest that the resource allocation related to port operations should receive more attention. Container shipping companies need to make appropriate berthing, stevedoring and warehouse arrangements in advance to handle related cargos. These measures can effectively reduce the probability of schedule delays.

The objective results show that the most important dimension is the planning dimension and the most important criteria are B4 (Chase strategy), A3 (Sailing schedule control) and A2 (Fleet allocation). These factors suggest that the shipping companies should implement necessary chase strategies, and moderate ship schedule arrangements and fleet allocation. Only seamless integration of related jobs can make the shipping companies achieve accurate ship schedules.

In the comparison analysis, the variances of subjective weights are lower than objective weights, because subjective weights have been identified by experts while the objective weights come from variance in performance of the container shipping companies. The subjective weights are more consistent than objective weights. The comparison analysis reveals that the criteria B4 (Chase strategy), A3 (Sailing schedule control), A2 (Fleet allocation), A4 (Transshipment arrangements) and A1 (Planning for ports along routes) may be ignored by the experts. The results suggest that the shipping companies should pay more attention to these factors and take action to improve their performance in relation to the criteria mentioned according to their relative importance to each company.

This study applied both subjective and objective weighting methods to identify the related criteria weights. Strategies for improvement can be derived from the criteria weights and the quadrant diagram. However, it is found that the criteria are not all independent, which means that there exist interrelations among them. These interrelations may influence the construction of related improvement strategies. This result leads to the suggestion that the DEMATEL method be combined with the other methods in order to deal with this problem. This may allow users to construct more effective strategies to improve this problem.

\section{References}

Abdul rahman, N. S. F., Othman, M. K., Sanusi, I. A., Arof, A. M., Ismail, A., 2019. Evaluation of delay factors on dry bulk cargo operation in Malaysia: A case study of Kemaman port. The Asian Journal of Shipping and Logistics 35, 127-137.

Brooks, M. R., 1990. Ocean carrier selection criteria in a new environment. Logistics and Transportation Review 26, 339-355. 
Chan, L. K., Wu, M. L., 2005. A systematic approach to quality function deployment with a full illustrative example. Omega 33, 119-139.

Chao, R. J., Chen Y. H., 2009. Evaluation of the criteria and effectiveness of distance e-learning with consistent fuzzy preference relations. Expert Systems with Applications 36, 10657-10662.

Chen, J., Zhang, S., Li, S., Zhang, F., Zhu, Y., Huang, X., 2018. Identifying critical factors of oil spill in the tanker shipping industry worldwide. Journal of Cleaner Production 180, 1-10.

Chen, J., Zhang, S., Xu, L., Wan, Z., Fei, Y., Zheng, T., 2019. Identification of key factors of ship detention under port state control. Marine Policy 102, 21-27.

Chung, C. C., Chiang, C. H., 2011. Critical factors in schedule reliability of container shipping carriers. Proceedings of World Multi-Conference on Systemics, Cybernetics and Informatics, Orlando, FL.

Ding, J. F., 2011. An integrated fuzzy TOPSIS method for ranking alternatives and its application. Journal of Marine Science and Technology 19, 341-352.

Herrera-Viedma, E., Herrera, F., Chiclana, F., Luque, M., 2004. Some issues on consistency of fuzzy preference relations. European Journal of Operational Research 154, 98-109.

Hoffmann, P., 1985. Performance Indicators and Productivity. Port Management Textbook Containerization, Bremen, Germany.

Hsiao, S. W., Chou, J. R., 2006. A Gestalt-like perceptual measure for home page design using a fuzzy entropy approach. International Journal of Human-Computer Studies 64, 137-156.

Jee, D. H., Kang, K. J., 2000. A method for optimal material selection aided with decision making theory. Materials and Design 21, 199-206.

Kaliszewski, A., Kozłowski, A., Dąbrowski, J., Klimek, H., 2020. Key factors of container port competitiveness: A global shipping lines perspective. Marine Policy 117, 103896.

Kristiansen, S., 2005. Maritime Transportation: Safety Management and Risk Analysis. Elsevier Butterworth-Heinemann, Oxford, UK.

Lee, P. T. W., Lin, C. W., Chung, Y. S., 2014. Comparison analysis for subjective and objective weights of financial positions of container shipping companies. Maritime Policy and Management 41, 241-250.

Lee, P. T. W., Lin, C. W., Shih, S. H., 2018. Financial performance evaluation of shipping companies using entropy and grey relation analysis. International Series in Operations Research and Management Science 260, 219-247.

Lee, S. W., Shin, S. H., Bae, H. S., 2020. Short sea shipping on the west coast of Korea: Keys to activating the shipping industry in preparation for Korea unification era. Journal of International Logistics and Trade 18, 91-105.

Li, Q., Meng, X.X., Liu, Y. B., Pang, L. F., 2019. Risk assessment of floor water inrush using entropy weight and variation coefficient model. Geotechnical and Geological Engineering 37, 1493-1501.

Li, X., Wang, K., Liu, L., Xin, J., Yang, H., Gao, C., 2011. Application of the entropy weight and TOPSIS method in safety evaluation of coal mines. Procedia Engineering 26, 2085-2091.

Lin, H., Pan, T., Chen, S., 2020. Comprehensive evaluation of urban air quality using the relative entropy theory and improved TOPSIS method. Air Quality Atmosphere \& Health. Available at: https://doi.org/10.1007/s11869-020-00930-7

Liu, F., Zhao, S., Weng, M., Liu, Y., 2017. Fire risk assessment for large-scale commercial buildings based on structure entropy weight method. Safety Science 94, 26-40.

Liu, L., Zhou, J., An, X., Zhang, Y. C., Yang, L., 2010. Using fuzzy theory and information entropy for water quality assessment in Three Gorges region, China. Expert Systems with Applications 37, 2517-2521.

Ma, J., Fan, Z. P., Huang, L. H., 1999. A subjective and objective integrated approach to determine attribute weights. European Journal of Operational Research 112, 397-404.

McGinnis, M. A., 1979. Shipper attitudes toward freight transportation choice: A factor analytic study. International Journal of Physical Distribution and Materials Management 10, 25-34.

Murphy, P. R., Dalenberg, D. R., Daley, J. M., 1991. Analyzing International water transportation: The perspectives of large U.S. industrial corporations. Journal of Business Logistics 12, 169-189.

Notteboom, T. E., 2006. The time factor in liner Shipping Services. Maritime Economic and Logistics 8, 19-39.

Pham, T. Y., Yeo, G. T., 2019. Evaluation of transshipment container terminals' service quality in Vietnam: From the shipping companies' perspective. Sustainability 11, 1503.

Plumlee, C. H., 1979. Port Performance Index. Public Works Consultants, Port Huenme, CA.

Seo, W., Ahn, S. B., 2019. A case study on logistics services preferences for supply chain entities in shandong province, China. Journal of International Logistics and Trade 17, 55-66. 
Shannon, C. E., 1948. A mathematical theory of communication. The Bell System Technical Journal 27, 379-423.

Slack, B., 1985. Containerization, Inter-port competition, and port selection. Maritime Policy and Management 1, 293-303.

Suthiwartnarueput, K., Lee, P. T. W., Lin, C. W., Visamitanan, K., Yang, Z., 2020. A trial to generalise evaluation of key driving factors of port-city waterfront development. International Journal of Shipping and Transport Logistics 12, 174-196.

Thomas, B. J., 1985. Operations Planning in Ports. University of Wales Institute of Science and Technology, Cardiff, UK.

Vernimmen, B., Dullaert, W., Engelen, S., 2007. Schedule unreliability in liner shipping: Origins and consequences for the hinterland supply chain. Maritime Economics and Logistics 9, 193-213.

Wang, T. C., Chen, Y. H., 2007. Applying consistent fuzzy preference relations to partnership selection. Omega 35, 384-388.

Weng, J., Yang, D., Chai, T., Fu, S., 2019. Investigation of occurrence likelihood of human errors in shipping operations. Ocean Engineering 182, 28-37.

$\mathrm{Xu}, \mathrm{X}$., 2004. A note on the subjective and objective integrated approach to determine attribute weights. European Journal of Operational Research 156, 530-532.

Yang, C. C., Chang, Y. K., 2019. Crucial factors influencing international logistics operations for African landlocked countries: A case study of Burkina Faso. Maritime Policy and Management, 46, 939-956.

Zhang, Y., Yang, Z., Li, W., 2006. Analyses of urban ecosystem based on information entropy. Ecological Modeling 197, 1-12.

Zou, Z. H., Yun, Y., Sun, J. N., 2006. Entropy method for determination of weight of evaluating in fuzzy synthetic evaluating for water quality assessment indicators. Journal of Environmental Science 18, 1020-1023. 